\section{KẾT LUÂN}

Qua nghiên của chúng tôi cho thấy AFP, AFPL3 và PIVKA-II có giá trị cao trong chẩn đoán ung thư biểu mô tế bào gan và bộ ba marker này sau điều trị 1 tháng và 3 tháng giảm có ý nghĩa so với trước điều trị.

\section{TÀI LIÊU THAM KHẢO}

1. Bertuccio $P$, Turati $F$, Carioli $G$, Rodriguez $T$, La Vecchia C, Malvezzi M, Negri E: Global trends and predictions in hepatocellular carcinoma mortality. Journal of hepatology 2017, 67(2):302-309.

2. Bosetti $C$, Turati F, La Vecchia C: Hepatocellular carcinoma epidemiology. Best practice \& research Clinical gastroenterology 2014, 28(5):753-770

3. Park H, Park JY: Clinical significance of AFP and PIVKA-II responses for monitoring treatment outcomes and predicting prognosis in patients with hepatocellular carcinoma. BioMed research international 2013, 2013:310427.
4. Song $\mathbf{P}$, Gao J, Inagaki $\mathbf{Y}$, Kokudo $\mathbf{N}$, Hasegawa $K$, Sugawara $\mathbf{Y}$, Tang $\mathbf{W}$ : Biomarkers: evaluation of screening for and early diagnosis of hepatocellular carcinoma in Japan and china. Liver cancer 2013, 2(1):31-39.

5. Lim TS, Kim DY, Han KH, Kim HS, Shin SH, Jung KS, Kim BK, Kim SU, Park JY, Ahn SH: Combined use of AFP, PIVKA-II, and AFP-L3 as tumor markers enhances diagnostic accuracy for hepatocellular carcinoma in cirrhotic patients. Scandinavian journal of gastroenterology 2016, 51(3):344-353.

6. Bertino G, Ardiri AM, Calvagno GS, Bertino N, Boemi PM: Prognostic and diagnostic value of des-y-carboxy prothrombin in liver cancer. Drug news \& perspectives 2010, 23(8):498-508.

7. Park WH, Shim JH, Han SB, Won HJ, Shin YM, Kim KM, Lim YS, Lee HC: Clinical utility of des- $\gamma$-carboxyprothrombin kinetics as a complement to radiologic response in patients with hepatocellular carcinoma undergoing transarterial chemoembolization. Journal of vascular and interventional radiology: JVIR 2012, 23(7):927-936.

\title{
THỰC TRANG TỔNG DUNG TÍCH PHỔI (TLC) Ở NGƯờI TIẾP XÚC TRỰC TIẾP BỤI SILIC TRONG MÔI TRƯỜNG LÀM VIỆC VÀ YẾU TỐ LIÊN QUAN
}

\author{
Nguyễn Ngọc Anh, Lê Thị Thanh Xuân, Nguyễn Thanh Thảo, \\ Lê Thị Hương, Phạm Thị Quân, Nguyễn Thị Quỳnh(*)
}

\section{TÓM TẮT}

Một nghiên cứu mô tả được thực hiện với mục tiêu đánh giá sự thay đổi tổng dung tích phổi (TLC) ở 869 đối tượng nghiên cứu là những người tiếp xúc trực tiếp bụi silic trong quá trình làm việc, đã được chụp phim xquang phối theo tiêu chuẩn ILO để chẩn đoán bụi phổi silic. Sau đó các đối tượng được đo chức năng hô hấp và đo tổng dung tích phổi (TLC). Kết quả cho thây: Tỷ lệ người lao động có giảm TLC là 10,5\% (91/869); có mối liên quan chặt chẽ giữa mắc bụi phổi silic đám mờ lớn với suy giảm TLC $(p<0,001)$; chưa thấy có mối liên quan giữa mắc bụi phổi silic nốt mờ nhỏ với sự suy giảm TLC ( $p>0,05)$; Có mối liên quan chặt chẽ giữa các mức độ giảm chỉ số FVC với giảm TLC trong phân tích đớn biến và đa biến $(p<0,001)$. Nên tiếp tục sử dụng các kỹ thuâat, chỉ số đo chức năng hô hấp thông thường như FVC để đánh giá giảm chức năng hô hấp hạn chế, trong trường hợp cần sự chính xác cao thì dùng chỉ số kỹ thuật cao TLC.

Tử khóa: Tổng dung tích phổi, chức năng hô hấp

\section{SUMMARY}

THE TOTAL LUNG CAPACITY AMONG

(*)Viên ĐT YHDP \& YTCC, Đai hoc Y Hà Nọi

Chịu trách nhiệm chính: Nguyễn Ngọc Anh

Email: anhnn@hmu.edu.vn

Ngày nhận bài: 14.9.2021

Ngày phản biên khoa hoc: 12.11.2021

Ngày duyệt bài: 19.11.2021

\section{WORKERS EXPOSED TO SILICA DUST IN} THE WORKPLACE AND RELATED FACTORS

This descriptive study aims to examine the changes in total lung capacity of workers who are directly exposed to silica in the workplace and related factors. Before measuring the respiratory function and total lung capacity (TLC), 869 workers in the environment exposed to silica dust had taken chest $\mathrm{x}$ rays to diagnose silicosis. The results show that: TLC reduction rate is $10.5 \%(91 / 869)$; there is a close relationship between having large cloud silicosis with TLC decline $(p<0.001)$; no association between small nodular silicosis and TLC decline $(p>0.05)$; There is a close relationship between the FVC reduction and TLC reduction $(p<0.001)$. It is recommended to continue to use common techniques and indicators of respiratory function such as FVC to assess limited respiratory function decline, in case high accuracy is required, the high technical index TLC should be used. function

Keywords; Total lung capacity, respiratory

\section{I. ĐẠT VẤN ĐỀ}

Tổng dung tích phổi (TLC) là lượng khí chứa trong phổi sau khi hít vào tối đa. Trung bình thể tích này ở người trưởng thành là khoảng 6 lít, tuy nhiên thể tích này còn phụ thuộc vào tuổi, giới, tình trạng cơ thể. TLC ở nam giới có xu hướng lớn hơn nữ, người có vóc dáng cao lớn hơn người thấp bé. Ngoài ra, TLC khác nhau ở 
từng cá nhân và bị ảnh hưởng bới mức độ hoạt động thể lực, tình trạng thành ngực, các bệnh đường hô hấp [1]. Vai trò quan trọng nhất của TLC là đánh giá tình trạng rối loạn thông khí hạn chế của phổi khi chỉ sổ dung tích phổi thở chậm (VC), dung tích thở ra gắng sức (FVC) giảm. Trên những người khỏe mạnh hoặc bệnh nhân có hội chứng hạn chế thật sự VC thường chiếm thể tích lớn trong tổng dung lượng phổi, vì vậy trên lâm sàng thường dùng VC và FVC để đánh giá mức độ hạn chế hơn là TLC [2]. Tuy nhiên khi nói đến sự hạn chế dung tích chứa khí của phổi thì chính xác là phải dùng chỉ số TLC. Nhiều nghiên cứu còn cho thấy chỉ số TLC nhạy hơn các chỉ số đánh giá dung tích phổi khác, nhưng do để có thể đo TLC cần có máy và thiết bị hiện đại, kỹ thuật tiên tiến [2], [3]. Khi làm việc trong môi trường có tiếp xúc trực tiếp với bụi silic, silic tự do trong bụi xâm nhập đường hô hấp sẽ có nguy cơ cao gây xơ hóa phổi, gây bệnh bụi phổi silic và các ảnh hưởng đến phổi phế quản khác. Hậu quả của xơ hóa phổi là sẽ làm dung tích phổi giảm, khả năng chứa đựng không khí của phổi giảm, sẽ làm hạn chế tổng dung tích phổi của đối tượng nên chỉ số tổng dung tích phổi (TLC) là chỉ số trực tiếp và chính xác để đánh giá [3].

A Goto và cộng sự đã nghiên cứu trên 130 người lao động có tiếp xúc với bụi silic và được chẩn đoán là mắc bệnh bụi phổi silic. Kết quả chỉ ra rằng các thông số về chức năng phổi đặc biệt là chỉ số TLC đều có bất thường và nhạy hơn VC hay FVC [4]. Để xem xét đánh giá toàn diện tác động của bụi silic đến chức năng phổi, từ đó có thể tìm kiếm các can thiệp kịp thời dự phòng bệnh bụi phổi silic cho người lao động, một bệnh nghề nghiệp phổ biến ở Việt Nam, bệnh tiến triển không hồi phục và cho đến hiện nay chưa có phương pháp điều trị đặc hiệu,nNghiên cứu được tiến hành nhằm mục tiều "Mố tả thực trạng tổng dung tích phổi ở người tiếp xúc trực tiếp với bưi silic trong quá trình lao động và một số yếu tố liên quan".

\section{II. ĐỐI TƯỢNG VÀ PHƯƠNG PHÁP NGHIÊN CỨU}

2.1. Đối tượng nghiên cứu. Người trực tiếp làm việc trong môi trường phát sinh bụi silic ở một số tỉnh miền Bắc và miền Trung, đảm bảo các tiêu chuẩn: thời gian làm việc trong môi trường có bụi silic $\geq 2$ năm; không mắc các bệnh tự miểm; không mắc bệnh tim mạch; không có tiền sử phẫu thuật lồng ngực; khổng mang thai và tự nguyện tham gia nghiên cứu.

2.2. Phương pháp nghiên cứu. Nghiên cứu mô tả cắt ngang, cỡ mấu toàn bộ (toàn bộ người lao động ở các cơ sở nghiên cứu thỏa mãn tiêu chuẩn đều được đưa vào nghiên cứu), chọn mẫu chủ đích, thực tế nghiên cứu đã tiến hành trên 796 người lao động đến từ 2 tỉnh Thái Nguyên và Hải Dương và 73 người mắc bụi phổi silic đến từ các tỉnh miền Bắc, miền trung.

2.3. Thời gian, địa điểm nghiên cứu. Thời gian thu thập số liệu năm 2020

Địa điểm đo đánh giá chỉ số chức năng hô hấp bao gồm tổng dung tích phổi TLC tại Bệnh viện Phổi trung ương (Hà Nội).

2.4. Công cụ và phương pháp thu thập: Toàn bộ đối tượng nghiên cứu trước đó đã được chụp X-quang chẩn đoán bệnh bụi phổi silic; và khai thác tiền sử, khám lâm sàng. Sau đó các đối tượng nghiên cứu được tập trung tại Bệnh viện phổi Trung ương để đo chức năng hô hấp kỹ thuật cao. Toàn bộ kỹ thuật đo, và đánh giá kết quả được thực hiện bởi các kỹ thuật viên thăm dò chức năng và bác sỹ hô hấp. Đánh giá TLC theo các mức: bình thường khi TLC $\geq 80 \%$; hạn chế nhe khi TLC 65\%-79\%; hạn chế trung bình khi TLC 50-64\%; hạn chế nặng khi TLC $<50 \%$ [2]

2.5. Xử lý và phân tích số liệu. Số liệu sau khi thu thập được làm sạch, nhập bằng phần mềm Epidata 3.1 và xử lý phân tích bằng phần mềm STATA

2.6. Đạo đức trong nghiên cứu. Nghiên cứu là một phần số liệu của đề tài khoa học cấp Nhà Nước "Nghiên cứu đặc điểm dịch tê̂̃ học phân tử, yếu tố nguy cơ và ứng dụng kỹ thuật tiên tiến trong chẩn đoán sớm bệnh bụi phổi silic tại Việt Nam" Mã số: KC.10.33/16-20 do Viện Đào tạo YHDP và YTCC, Trường Đại học Y Hà Nội thực hiện, và đã được ban chủ nhiệm Đề tài cho phép sử dụng số liệu. Đề tài được Hội đồng đạo đức Trường Đại học Y Hà Nội thổng qua, mã số 4218/HMUIRB ngày 16/11/2018.

\section{KẾT QUẢ NGHIÊN CứU}

Bảng 3.1. Đặc điểm chung của đôi tượng nghiên cứu (n=869)

\begin{tabular}{|c|c|c|c|}
\hline \multicolumn{2}{|c|}{ Đặc điểm } & Số lượng & Tỷ lệ \% \\
\hline \multirow{2}{*}{ Giới tính } & Nam & 789 & 90,8 \\
\cline { 2 - 4 } & Nũ̃ & 80 & 9,2 \\
\hline Nhóm tuổi & $\leq 29$ tuổi & 413 & 47,5 \\
\hline
\end{tabular}


VIETNAM MEDICAL JOURNAL N²0 - DECEMBER - 2021

\begin{tabular}{|c|c|c|c|}
\hline \multirow{4}{*}{$\begin{array}{c}\text { Nhóm tuổi nghề (thâm niên làm } \\
\text { việc tiếp xúc bụi silic) }\end{array}$} & 30 tuối -49 tuối & 341 & 39,2 \\
\cline { 2 - 4 } & $\geq 50$ tuối & 115 & 13,2 \\
\cline { 2 - 4 } & $<5$ năm & 70 & 8,1 \\
\cline { 2 - 4 } & 5 năm -9 năm & 158 & 18,2 \\
\cline { 2 - 4 } & 10 năm -14 năm & 360 & 41,4 \\
\hline \multirow{2}{*}{ Bệnh bụi phổi silic } & 15 năm -19 năm & 98 & 70 \\
\hline & $\geq 20$ năm & 183 & 21,1 \\
\cline { 2 - 4 } & Không mắc & 526 & 60,5 \\
\hline
\end{tabular}

Nhân xét: Trong tống số 869 người tham gia nghiên cứu có $90,8 \%$ là nam và $9,9 \%$ là nữ. Độ tuổi chiếm tỉ lệ nhiều nhất là dưới 30 tuổi chiếm 47,5\%. Đa số đối tượng có tuổi nghề từ 10-14 năm chiếm 41,4\%. Có 343 trên tổng số 869 đối tượng tham gia vào nghiên cứu được chẩn đoán mắc bệnh bụi phổi Silic (39,5\%).

Bảng 3.2. Thực trạng các chỉ số chức năng hô hấp chính (FVC, FEV1, TLC, DLCO) của đôi tượng nghiên cứu

\begin{tabular}{|c|c|c|c|c|c|c|c|c|c|}
\hline \multirow{2}{*}{\multicolumn{2}{|c|}{ Đặc điểm }} & \multicolumn{2}{|c|}{ FVC giảm } & \multicolumn{2}{|c|}{ FEV1 giảm } & \multicolumn{2}{|c|}{ TLC giảm } & \multicolumn{2}{|c|}{ DLCO giảm } \\
\hline & & SL & $\%$ & SL & $\%$ & SL & $\%$ & SL & $\%$ \\
\hline \multirow{3}{*}{$\begin{array}{l}\text { Nhóm } \\
\text { tuổi }\end{array}$} & $\leq 29$ tuối $(n=413)$ & 56 & 13,6 & 37 & 9,0 & 35 & 8,5 & 6 & 1,5 \\
\hline & $30-49$ tuối $(n=341)$ & 68 & 19,9 & 78 & 22,9 & 43 & 12,6 & 36 & 10,6 \\
\hline & $\geq 50$ tuổi $(n=115)$ & 16 & 13,9 & 28 & 24,3 & 13 & 11,3 & 18 & 15,7 \\
\hline \multirow{5}{*}{$\begin{array}{c}\text { Nhóm } \\
\text { tuổi } \\
\text { nghề }\end{array}$} & $<5$ năm $(\mathrm{n}=70)$ & 16 & 22,9 & 17 & 24,3 & 13 & 18,6 & 8 & 11,4 \\
\hline & $5-9$ năm $(n=158)$ & 32 & 20,3 & 30 & 19 & 28 & 17,7 & 20 & 12,7 \\
\hline & $10-14$ năm $(n=360)$ & 49 & 13,6 & 45 & 12,5 & 35 & 9,7 & 19 & 5,3 \\
\hline & $15-19$ năm $(n=98)$ & 18 & 18,4 & 17 & 17,3 & 6 & 6,1 & 3 & 3,1 \\
\hline & $\geq 20$ năm $(n=183)$ & 25 & 13,7 & 34 & 18,6 & 9 & 4,9 & 10 & 5,5 \\
\hline & ổng ( $\mathrm{n}=869)$ & 140 & 16,1 & 143 & 16,5 & 91 & 10,5 & 60 & 6,9 \\
\hline
\end{tabular}

Nhận xét: Nhóm tuối từ 30 đến 49 tuối là nhóm tuổi có tỉ lệ suy giảm FVC cao nhất $(19,9 \%), 2$ nhóm tuổi là dưới 30 là trên 50 có tỉ lệ thấp hơn lần lượt là $13,6 \%$ và $13,9 \%$. Tuổi càng cao thì tỉ lệ suy giảm FVC càng tăng, nhóm tuổi 30-49 tuổi: 22,9\% và trên 50 tuổi chiếm chỉ $24,3 \%$ trong khi nhóm dưới 30 tuổi là 9,0\% TLC và DLCO cũng có tỉ lệ suy giảm cao hơn ở những đối tượng có nhóm tuổi càng cao

Xét theo nhóm tuối nghề của đối tượng tham gia nghiên cứu, khoảng $1 / 5$ đối tượng có tuổi nghề dưới 9 năm có suy giảm FVC, sau đó là nhóm tuổi nghề $15-19$ năm $(18,4 \%)$ và thấp hơn ở 2 nhóm tuổi nghề còn lại là $10-14$ năm và trên 20 năm. Dưới 5 năm là nhóm tuổi nghề có tỉ lệ suy giảm FEV1 cao nhất (24,3\%), tỉ lệ này thấp hơn ở các nhóm tuổi nghề khác. Dưới 9 năm cũng là nhóm tuổi nghề có tỉ lệ suy giảm TLC và DLCO cao hơn các nhóm tuổi nghề còn lại.

Bảng 3.3. Môi liên quan đơn biến giữa mắc bệnh bụi phổi silic và chỉ số TLC

\begin{tabular}{|c|c|c|c|c|c|c|}
\hline \multirow{2}{*}{ Đặc điểm } & \multicolumn{2}{|c|}{ Giảm TLC } & \multicolumn{2}{|c|}{ Không giảm TLC } & \multirow{2}{*}{ OR (95\% CI) } & \multirow{2}{*}{$\mathbf{p}$} \\
\cline { 2 - 5 } & $\mathbf{S L}$ & $\mathbf{\%}$ & $\mathbf{S L}$ & $\mathbf{\%}$ & & - \\
\hline Không mắc bệnh $(\mathrm{n}=526)$ & 43 & 8,2 & 483 & 91,8 & 1 & - \\
\hline Mắc bụi phổi silic $(\mathrm{n}=343)$ & 48 & 14 & 295 & 86,0 & $1,82(1,18-2,87)$ & 0,007 \\
\hline Tốn thương nốt mờ nhỏ $(\mathrm{n}=294)$ & 25 & 8,5 & 269 & 91,5 & $1,044(0,64-1,77)$ & 0,87 \\
\hline $\begin{array}{c}\text { Tổn thương đám mờ lớn } \\
(\mathrm{A}, \mathrm{B}, \mathrm{C})(\mathrm{n}=49)\end{array}$ & 23 & 46,9 & 26 & 53,1 & $9,94(5,22-18,88)$ & 0,000 \\
\hline
\end{tabular}

Nhận xét: Tỷ lệ suy giảm TLC nhóm mắc bệnh bụi phổi silic (14\%) cao hơn nhóm mắc bệnh bụi phổi silic $(8,2 \%)$. Trong nhóm mắc bệnh, tỷ lệ suy giảm TLC của nhóm có tổn thương nốt mở lớn $(46,9 \%)$ cao hơn nhóm có tổn thương đám mờ nhỏ $(8,5 \%)$. So với nhóm không mắc bệnh bụi phổi silic thì nguy cơ suy giảm TLC ở nhóm mắc bệnh cao gấp 1,82 lần và ở nhóm có tổn thươning đám mờ lớn cao gấp 9,94 lần. Sự khác biệt có ý nghĩa thống kê với $p<0,05$.

Bảng 3.4. Mối liên quan đớn biến giữa chỉ số FVC và TLC của đôi tượng nghiên cứu

\begin{tabular}{|c|c|c|c|c|c|c|}
\hline \multirow{2}{*}{ Đặc điểm } & \multicolumn{2}{|c|}{ Giảm TLC } & \multicolumn{2}{|c|}{ Không giảm TLC } & \multirow{2}{*}{ OR (95\% CI) } & \multirow{2}{*}{ p } \\
\cline { 2 - 5 } & SL & $\mathbf{9}$ & SL & \% & & - \\
\hline FVC bình thường $(\mathrm{n}=\mathbf{7 2 9})$ & 32 & 4,4 & 697 & 95,6 & 1 & - \\
\hline
\end{tabular}




\begin{tabular}{|c|c|c|c|c|c|c|}
\hline $\begin{array}{l}\text { FVC \% giảm mức độ nhẹ } \\
(\mathrm{n}=110)\end{array}$ & 43 & 39,1 & 67 & 60,9 & $13,97(8,29-23,55)$ & 0,000 \\
\hline $\begin{array}{l}\text { FVC \% giảm mức độ vừa } \\
(\mathrm{n}=15)\end{array}$ & 10 & 66,7 & 5 & 33,3 & $43,56(14,06-134,92)$ & 0,000 \\
\hline $\begin{array}{c}\text { FVC \% giảm mức độ nặng } \\
(\mathrm{n}=15)\end{array}$ & 6 & 40 & 9 & 60,0 & $14,52(4,87-43,27)$ & 0,000 \\
\hline
\end{tabular}

Nhận xét: Tỷ lệ suy giảm TLC trong nhóm có chỉ số FVC bình thường chiếm 4,4\%. Còn trong nhóm có suy giảm chỉ số FVC thì tỷ lệ này cao hơn, cụ thể cao nhất là FVC \% giảm mức độ vừa $(66,7 \%)$, thấp hơn ở nhóm FVC \% giảm mức độ nặng (40\%) và FVC \% giảm mức độ nhẹ (39,1\%). So với nhóm không suy giảm FVC thì sự suy giảm TLC ở các nhóm có suy giảm FVC cao gấp nhiêu lần: FVC \% giảm mức độ vừa 43,56 lần, nhóm FVC \% giảm mức độ nặng 14,52 lần và FVC \% giảm mức độ nhẹ là 13,97 lần. Sự khác biệt đều có ý nghĩa thống kê với p<0.05.

Bảng 3.5. Phân tích đa biến giữa mắc bụi phổi silic và giảm FVC với giảm TLC

\begin{tabular}{|c|c|c|c|c|c|c|}
\hline \multirow{2}{*}{ Đặc điểm } & \multicolumn{2}{|c|}{ Có giảm TLC } & \multicolumn{2}{|c|}{$\begin{array}{l}\text { Không giảm } \\
\text { TLC }\end{array}$} & \multirow{2}{*}{ OR (95\% CI) } & \multirow{2}{*}{ p } \\
\hline & $\mathbf{S L}$ & $\%$ & SL & $\%$ & & \\
\hline \multicolumn{7}{|c|}{ Bệnh bụi phổi silic } \\
\hline Không mắc bệnh ( $\mathrm{n}=526)$ & 43 & 8,2 & 483 & 91,8 & 1 & - \\
\hline $\begin{array}{c}\text { Mắc bệnh bụi phổi có đám mờ } \\
\text { nhỏ }(n=294)\end{array}$ & 25 & 8,5 & 269 & 91,5 & $0,99(0,56-1,73)$ & 0,974 \\
\hline $\begin{array}{c}\text { Mắc bệnh bụi phổi có đám mờ } \\
\text { lớn }(n=49)\end{array}$ & 23 & 46,9 & 26 & 53,1 & $5,46(2,50-11,93)$ & 0,000 \\
\hline \multicolumn{7}{|c|}{ Chỉ số FVC } \\
\hline Không suy giảm FVC $(\mathrm{n}=729)$ & 32 & 4,4 & 697 & 95,6 & 1 & - \\
\hline $\begin{array}{l}\text { Suy giảm FVC mức độ nhẹ } \\
\qquad(n=110)\end{array}$ & 43 & 39,1 & 67 & 60,9 & $\begin{array}{c}12,70(7,44- \\
21,70)\end{array}$ & 0,000 \\
\hline $\begin{array}{l}\text { Suy giảm FVC mức độ vừa } \\
\qquad(n=15)\end{array}$ & 10 & 66,7 & 5 & 33,3 & $\begin{array}{l}25,33(7,25- \\
85,30)\end{array}$ & 0,000 \\
\hline $\begin{array}{l}\text { Suy giảm FVC mức độ nặng } \\
\qquad(n=15)\end{array}$ & 6 & 40 & 9 & 60,0 & $\begin{array}{c}11,59(3,66- \\
36,67) \\
\end{array}$ & 0,000 \\
\hline
\end{tabular}

Nhận xét: Trong vấn đề mắc bệnh bụi phổi silic: Đối tượng mắc bệnh và tổn thương đám mở lớn ở phổi thì có nguy cơ giảm TLC cao gấp 5,46 lần so với nhóm không mắc bệnh. Về chức năng hô hấp: Đối tương có suy giảm FVC đều làm tăng nguy cơ giảm TLC cụ thể với suy giảm FVC mức độ vừa nguy cơ là 25,33 lần, mức độ nhẹ gấp 12,709 lần và mức độ năng gấp 11,59 lần. Sự khác biệt có ý nghĩa thống kê với $p<0,05$.

\section{BÀN LUẬN}

Kỹ thuật đã đo tổng dung tích phổi (TLC) được thực hiện tại Bệnh viện Phổi trung ương trên tổng số 896 đối tượng tiếp xúc bụi silic trong quá trình lao động. Trong đó có 796 người lao động vẫn đang làm việc và 73 người là các bệnh nhân bụi phổi silic đến điều trị tại Bệnh viện Phổi trung ương.

Đặc điểm sức khỏe nghề nghiệp chung và đặc điểm mắc bệnh bụi phổi silic, được thu thập trước khi đo chức năng hô hấp và TLC của các đối tượng nghiên cứu. Cũng tương tự như các nghiên cứu về bệnh bụi phổi silic khác và trong nghiên cứu này, đa số đối tượng nghiên cứu là nam giới, tỉ lệ nam giới trong nghiên cứu là đa số chiếm 90,8\%. Dưới 30 tuổi là nhóm tuổi chiếm tỉ lệ cao nhất trong nhóm đối tượng nghiên cứu $(47,5 \%)$, kết quả nghiên cứu tương đồng với kết quả nghiên cứu của Trịnh Hồng Lân và Huỳnh Thanh Hà (2008) [6]. Về các đặc điểm có mắc bệnh bụi phổi silic của đối tượng nghiên cứu đánh giá TLC chiếm 39,5\%, trong nghiên cứu này không đại diện cho tỷ lệ người lao động ở các nhóm ngành nghề này nói chung mắc bụi phổi silic bởi đây là nghiên cứu nhằm mục đích xem xét các yếu tố tác động đến tổng dung tích phổi (TLC) ở những người lao động làm việc có tiếp xúc trực tiếp với bụi silic.

Kết quả nghiên cứu ở bảng 3.2 cho thây đối tượng có tuổi đời từ 30 tuổi trở lên thì có nguy cơ giảm các chỉ số chức năng hô hấp chính bao gồm cả chỉ số về thông khí và chỉ số về trao đổi khí (FVC, FEV1, TLCV và DLCO) cao hơn so với nhóm dưới 30 tuổi. Khoa học chỉ ra rằng đến tuổi 40, một số yếu tố như lồng ngực biến dạng, các khớp bị cứng, nhu mô phổi giảm đàn hồi, 
kết hợp với sự xơ cứng ở cơ bắp và xương sườn buồng phổi có thể khiến cho nhiều người bị khó thở, khả năng trao đổi khí càng giảm dẫn đến chức năng hô hấp giảm hơn so với người trẻ [6]. Bảng kết quả 3.3 và 3.5 đã phân tích sự liên quan giữa mắc bệnh bụi phổi silic và dung tích sống gắng sức (FVC) với chỉ số tổng dung tích phổi TLC. Kết quả cho thấy mặc dù chưa mắc bệnh bụi phổi silic cũng như các bệnh hô hấp và không có những bất thường lồng ngực (đã được loai trừ khi chọn đối tượng nghiên cứu), nhưng vẫn có $8,2 \%$ giảm $T L C$, và thấy rất rõ tỷ lệ giảm TLC tăng lên ở nhóm mắc bệnh bụi phổi silic (14\%), tỷ lệ giảm TLC tăng theo mức độ nặng của bênh bui phổi silic. Trong số 49 đối tượng mắc bụi phổi silic đám mờ lớn $(A, B, C)$ có đến 23 người suy giảm TLC chiếm $46,9 \%$. Điều này cho thấy rõ ràng rằng bụi phổi silic đã tác động đến tổng dung tích phổi tuy nhiên ở nhóm chưa phát hiện được các tổn thương của bệnh bụi phổi silic qua hình ảnh Xquang vẫn có một tỷ lệ nhất định giảm TLC. Điều này đặt ra vấn đề, liệu có thể những người suy giảm TLC này là các trường hợp biểu hiện sớm của tình trạng tác động của bụi silic đến chức năng phổi nên trên hình ảnh Xquang chưa phát hiện được bệnh. Từ kết quả nghiên cứu này cho thây rất cần thiết phải có những nghiên cứu dọc theo dõi sát sao để phát hiện bệnh bụi phổi silic ở nhóm đối tượng này.

Trong phân tích đơn biến, kết quả chỉ ra rằng đối tượng mắc bệnh bụi phổi silic có nguy cơ giảm TLC cao gấp 1,82 lần với nhóm không không mắc bệnh. So với nhóm không mắc bệnh bụi phổi, nhóm đối tượng có tổn thương đám mờ nhỏ trên phim Xquang phổi thì nguy cơ giảm TLC cao gấp 1,04 lần, trong khi đó nhóm có tổn thương đám mờ lớn cao gấp 9,93 lần. Điều này phù hợp với sinh bệnh học của bệnh bụi phổi là một bệnh xơ hóa nhu mô phồi làm giảm tính đàn hồi của nhu mô, giảm khả năng chứa đựng không khí của phổi dẫn đến tổng dung lượng phổi (TLC) giảm [3]. Trong nghiên cứu của mình, tác giả Gabriella Guamieri và cộng sự đã cho rằng trong nhóm mắc bệnh bụi phổi silic, sự thay đổi phổ biến nhất là mồ hình hạn chế dựa trên TLC và sự suy giảm của DLCO [7]. Kết quả nghiên cứu cũng cho thấy mối liên quan giữa mức độ giảm FVC\% với nguy cơ suy giảm TLC. So với nhóm đối tượng có FVC\% bình thường, nhóm có FVC\% giảm mức độ nhẹ cao hơn 13,97 lần, nhóm người có $\mathrm{FVC} \%$ giảm mức độ vừa cao gấp 43,56 lần và những người có $\mathrm{FVC} \%$ giảm mức độ nhe cao gấp 14,521 lần. Hiện nghiên cứu về mối liên quan giữa FVC\% và TLC còn hạn chế nên trong tương lai cần được nghiên cứu thêm.

Khi phân tích đa biến về tình trạng mắc bệnh bụi phổi silic và mức độ giảm FVC\% với tỷ lệ giảm TLC bằng mô hình hồi quy đa biến, kết quả cho thấy nhóm đối tượng có tổn thương đám mò lớn trên phim Xquang phổi có nguy cơ giảm TLC cao gấp 5,46 lần so với nhóm không mắc bệnh. Về mức độ suy giảm FVC\% kết quả cho thấy những đối tượng có giảm FVC\% ở tất cả các mức độ từ nhe đến nặng thì có giảm TLC cao hơn nhóm có FVC\% bình thường $(p<0,0001)$.

\section{KẾT LUẬN}

Nghiên cứu của chúng tôi cho thấy trong số 869 đối tượng nghiên cứu có làm việc trong môi trường tiếp xúc trực tiếp bụi silic có 91 (10,5\%) trường hợp có suy giảm TLC; có mối liên quan chặt chẽ giữa mắc bụi phổi silic đám mờ lớn với suy giảm TLC $(p<0,001)$; chưa thấy có mối liên quan giữa mắc bụi phổi silic nốt mờ nhỏ với sự suy giảm TLC $(p>0,05)$; Có mối liên quan chặt chẽ giữa các mức độ giảm chỉ số FVC với giảm TLC trong phân tích đơn biến và đa biến $(p<0,001)$. Nên tiếp tục sử dụng các kỹ thuật, chỉ số đo chức năng hô hấp thông thường như FVC để đánh giá giảm chức năng hô hấp hạn chế, trong trường hợp cần sự chính xác cao thì dùng chỉ số kỹ thuật cao TLC.

\section{TÀl LIỆ THAM KHẢO}

1. Delgado, J B, Tushar Bajaj. Physiology, Lung Capacity. StatPearls [Internet]. 2019;

2. GL Ruppel. What is the clinical value of lung volumes? Respiratory care. Jan 2012;57(1):26-35; discussion 35-8. doi:10.4187/respcare.01374

3. Khương Văn Duy. Bệnh bụi phổi silic (Silicosis) nghề nghiệp. Bệnh nghề nghiệp - Giáo trình đào tao sau đai hoc. Nhà xuất bản Y học: Đại học Y Hà Nội; 2017. 64-81

4. Goto A, Nawata S. [Clinical analysis of 130 cases of Siberian silicosis]. Nihon Igaku Hoshasen Gakkai Zasshi. 1995;55(3):121-128.

5. Trịnh Hồng Lân, Huỳnh Thanh Hà. Khảo sát tình hình bệnh nhiễm bựi phổi silic nghề nghiệp tai một số cơ sở sản xuất vật liệu xây dựng thuộc công ty xây dựng Dĩ An - Bình Dương. Tạp chí Y Y học TP Hồ Chí Minh. 2008;12(4):trang 240-246.

6. Lưu Phương Lan. Đặc điểm lâm sàng, cận lâm sàng và chức năng thổng khí phổi ở bệnh nhân xơ cứng bì hệ thống. Luận án tiến sĩ y học, Đại học Y Hà Nội. 2015;

7. Guarnieri G, Mauro S, Lucernoni $\mathbf{P}$, et al. Silicosis in finishing workers in quartz conglomerates processing. Med Lav. 2020;111(2):99-106. doi:10.23749/ mdl.v111i2.9115 